\title{
AUTORIA, ORIGINALIDADE E DIVULGAÇÃO: QUESTÕES ABERTAS
}

\author{
Maria Marta Furlanetto* \\ Universidade do Sul de Santa Catarina \\ Programa de Pós-Graduação em Ciências da Linguagem \\ Tubarão, SC, Brasil
}

\begin{abstract}
"Para sobreviver, é preciso avançar disfarçado e não revelar nada a ninguém, nem mesmo a si próprio."
\end{abstract}

(Michel Maffesoli)

"Comunicação e informação dão nova potência a um dos mais sólidos arcaísmos: estar em relação. Mesmo se agora se trata de relações mediadas tecnologicamente."

(Michel Maffesoli)

Em nossa edição 2018-1 desenvolvemos um episódio que teve como fio condutor o plágio e o autoplágio, tomados como males que afetam, moral e eticamente falando, a produção científica e sua divulgação, e cuja circulação se origina num ponto sensível, no que nos diz respeito: o espaço editorial no âmbito das universidades. Mais especificamente, falamos de editorias gerenciadas do modo como nós o fazemos: trabalhando e fazendo circular gratuitamente o saber produzido nos centros de pesquisa e especialmente nos programas de pós-graduação, com a inescapável consultoria de pesquisadores que, sem visível valoração de seu trabalho - o que está a exigir uma posição mais decisiva junto à Coordenação de Aperfeiçoamento de Pessoal de Nível Superior -, permitem que haja a necessária filtragem e avaliação de trabalhos para garantir a relevância do que é publicado.

Anotamos, na ocasião, que, em se tratando do meio em que exercemos nossas funções e daquilo que projetamos nas condições existentes de trabalho, teríamos de descartar a ingenuidade como argumento (menos ainda pretexto) para incidir em plágio e autoplágio na produção científica. Chega a ser assustador tomar conhecimento da quantidade de materiais publicados que se voltam para esse tema, a exemplo da obra indicada em nossa edição anterior: Plágio acadêmico, de Wachowicz e Costa (2016), editado em e-book.

A pletora desses materiais leva a perguntar: em que ponto do caminho histórico se tornou necessário atentar para esse fenômeno, e por que se manifestou aquilo que esses instrumentos (livros, manuais, artigos, cartazes, programas de detecção) querem prevenir,

\footnotetext{
* Doutora em Linguística Aplicada pela Université Paris VIII. Docente do Programa de Pós-graduação em Ciências da Linguagem da Universidade do Sul de Santa Catarina. Editora de Linguagem em (Dis)curso. E-mail: mmartafurlanetto@gmail.com.
} 
corrigir - ou funcionar como alerta e mesmo como ameaça? Como sabemos, acima de todos esses instrumentos imediatos se encontra a Lei 9.610, de 19 de fevereiro de 1998, emitida pela Presidência da República.

Como se vê, continuamos a perspectivar o tema que, no mundo da produção científica geral, afeta todos nós: a figura autoral e suas vicissitudes. Tomamos, desta vez, ângulos diferentes da questão para expandir a discussão e mergulhar em aspectos que nos ajudem a compreender por que nos encontramos vivendo em espaços em que predomina uma desconfiança quase mesquinha, e no mínimo desconcertante - e como emergir deles ou transformá-los. É inevitável presumir que, ao virem à tona - ressurgindo - formas de manifestação repetitivas, cabe enxergar aí indícios de um problema, uma crise, uma doença social - que racha o cimento (o imaginário) que nos agrupa.

\section{PANORAMA DO MUNDO GLOBALIZADO E INTERNACIONALIZAÇÃO}

Para introduzir certas características que parecem atadas ao que se entende como mundo globalizado, certa percepção de uma teia de uniformização que se estende invisivelmente (mas com consequências visíveis e sensíveis), comecemos por uma noção desenvolvida no espaço da Sociologia. Priorizamos aqui a sociologia compreensiva de Michel Maffesoli.

Todas as sociedades, todas as culturas estão sobredeterminadas por aquilo que Maffesoli chamou imaginário, que não é, de saída, algo que se opõe a real ou realidade. Se a cultura (antropologicamente considerada) contém imaginário, também não se reduz ao imaginário, da mesma forma que o imaginário não se reduz à cultura, que apresenta fenômenos e elementos passíveis de descrição. A noção (e não conceito, que tem caráter racional) de imaginário "tem, além disso, algo de imponderável. É o estado de espírito que caracteriza um povo." (MAFFESOLI, 2001, p. 75). Por isso, compõe características que o autor enquadra como ordem espiritual, matriz, atmosfera, ambiente, e também o que Walter Benjamin chamou de aura, algo sensível mas não visível; algo que ultrapassa as obras da cultura. Como tal, Maffesoli não pode entender o imaginário como marca do indivíduo, mas apenas como fenômeno coletivo. Um exemplo, para ele muito nítido, é o que denomina tribalismo na cultura pós-moderna - e não individualismo, como se poderia pensar em outra vertente, considerando a conjuntura sociopolítica e econômica do mundo contemporâneo. O tribalismo sempre congrega grupos com elementos e interesses em comum; o imaginário seria o elemento que forma essa atmosfera que liga pessoas.

Imaginário faz lembrar imagem (polissemicamente variável). Maffesoli salienta que é o imaginário que produz imagens, como resultado, não o contrário: isso vale para o cinema, a pintura, a escultura, a arquitetura, a decoração, as tecnologias. Mas, ao mesmo tempo, o imaginário é alimentado pela tecnologia.

Muito especialmente, o autor busca demarcar essa noção daquelas de ideologia e de inconsciente. Se, ainda hoje, ideologia permite uma variedade de percepções, observese que Maffesoli a toma como semelhante a imaginário justamente em sua concepção original, quando Destutt de Tracy a criou no início do século XIX: "conjunto orgânico de ideias" - apenas isso. Maffesoli recusa, no que foi desenvolvido e percebido como ideologia, um caráter racional, pelo que pode, nela, ser interpretado, explicado, explicitado, até desvendado. Ele não integra tais atributos no imaginário. O imaginário é 
mais sutil, reunindo parâmetros como "o onírico, o lúdico, a fantasia, o imaginativo, o afetivo, o não racional, o irracional, os sonhos, enfim, as construções mentais potencializadoras das chamadas práticas.” (2001, p. 76-77). O laço social é um fator premente nessa composição: faz-se cimento para criar relações, de onde se pode entender que o autor dê destaque ao processo de interação, de relação, relacionamento, partilha. Por isso, indivíduo, em sua percepção, estaria superado - tudo se imita (heteronomia), se faz com, seguindo percepções que impregnam grupos:

\begin{abstract}
O termo indivíduo, já o disse, parece-me superado, ao menos no sentido estrito. Talvez se deva falar, quanto à pós-modernidade, em uma persona que desempenha diversos papéis nas tribos às quais adere. A identidade fragiliza-se. As diferentes identificações, em contrapartida, multiplicam-se.
\end{abstract}

As grandes reuniões musicais, esportivas, consumistas, demonstram isso. Em cada um desses casos, trata-se de se perder no outro. (MAFFESOLI, 1998, p. 12)

Uma persona, poderíamos adiantar, é aquela que se põe no papel de escritor, exercendo uma função subjetiva possível - entre outras - e que adota um posicionamento em seu meio social, com direcionamento perceptível, em suas variações na multiplicidade de ouvintes/leitores intérpretes.

Há, assim, por parte do autor, insurgência contra os esquemas binários que encontramos nas sociedades, com um polo correto e outro subversivo, sempre em confronto, como direita e esquerda. Ele vê, antes disso, os interstícios e os deslizamentos, observando a complexidade dos grupos sociais. Racionalizar é dividir, enrijecer, ao passo que o imaginário, nessa linha de pensamento, seria um jogo maleável entre o que Mafessoli chama "intimações objetivas" (o que é imposto aos sujeitos vivendo em sociedade) e subjetividade, entre coerções sociais e subjetividade - o jogo, pode-se dizer, que é preciso jogar para viver.

Em Liberdades intersticiais, Maffesoli (1993, p. 53) explicita certas formas de "desestabilizar o político, de mostrar sua relatividade e aspecto limitado." Estamos falando desse jogo de tornar a vida social algo mais que uma sequência de ordenações impostas, com medidas que ele exemplifica com "a abstenção, a astúcia, a ironia, a inversão carnavalesca", nada trágicas em relação às greves, às manifestações de massa, às explosões catastróficas. São "pequenas utopias intersticiais" para a conservação de grupos. Em expressão compreensível, seria algo como "fazer corpo mole" e tomar atitudes contraditórias relativamente ao que se esperaria a partir de certas presunções ou estatísticas do mundo normalizado - como em eleições, por exemplo. São traços de resistência, meio subterrânea, meio cínica, meio inconsciente. Afinal, o próprio mundo político e diplomático vive de "jogo duplo" - que, diga-se se passagem, exige razoável controle do regime do silêncio: não dizer, dizer pela metade, esconder; dizer publicamente/dizer em off.

Assim, frente a diversas imposições sócio-político-econômicas, podemos dobrar sem quebrar, podemos aceitar as ideologias "da boca para fora" e acionar o mecanismo de restrições mentais, podemos "fazer de conta" que aceitamos as morais estabelecidas, as religiões dominantes e as diversas injunções sociais, sempre guardando "distância". (MAFFESOLI, 1993, p. 58) 
Essas manifestações do jogo duplo têm importância fundamental no mundo do trabalho. Conta Maffesoli que, correlativamente à exploração das populações pelo mundo produtivista burguês, no século XIX, logo surgiu um "código" operário de práticas astuciosas para sobrevivência. Essas práticas, certamente, perduram no mundo contemporâneo em todas as áreas, não apenas no mundo do operariado, mas dos servidores em geral: pequenas comemorações, mercado informal para venda de livros e outros objetos, por exemplo. São práticas, todas elas, para "salvaguardar o equilíbrio físico e psicológico, gravemente ameaçado.” (MAFFESOLI, 1993, p. 65).

Não se pode excluir do jogo duplo também o próprio âmbito do lúdico, do entretenimento, da diversão: jogos esportivos (como a Copa do Mundo de futebol do ano corrente), festas públicas e privadas, o carnaval - teatralização, mascaramento, realidade alternativa. A publicidade e os serviços de turismo baseiam sua sedução nesse jogo duplo. Há aí, diz Maffesoli, além de consumo, consumação.

A grande lição que se deprende daqui é que, "ao invés de ser manipulada, como é comum acreditar-se ou tentar fazer crer, a massa determina-se por si própria. Ou, ao menos, segue modas que não obedecem somente aos meros cálculos racionais e prognósticos de autoridades eminentes." (MAFFESOLI, 1993, p. 68). De certa forma, é em segredo e em semiconsciência que essa socialidade se firma - que isso se faz acontecimento - na estrutura e solapando a estrutura.

Tudo isso implica a noção de comunicação, como faz notar Maffesoli (2003): comunicação é encontro para compreender - e compreender é, no sentido etimológico, "pegar com, tomar junto, reunir, abordar o mundo na sua totalidade, abrir-se aos outros." (p. 14). E encarna o imaginário. O problema, salienta o autor, é "o monopólio das palavras informação e comunicação pela intelligentsia, os intelectuais hegemônicos, que não presta atenção ao sentido profundo desses termos." (p. 14). É que informação é pôr em forma, o que é praticamente redundante ao lado de comunicação. Ambas levam à expressão do desejo de participação, de troca, embora haja, na ideia de informação, um traço utilitário. Desse modo, mais do que a pretensa objetividade do informar, o que os próprios meios de comunicação fazem não tem universalidade; atingem mais especificamente grupos pequenos, regiões, tribos. Eles têm, aliás, público-alvo definido. E para o público em geral, diz Maffesoli, o que conta especialmente é o que possa dizer respeito à forma e estilo de vida de cada um ou cada grupo, em sua necessidade de vínculos emocionais. Essa orientação deve ser o que justifica o incremento das redes sociais, cujos criadores devem reconhecer tal necessidade, ultrapassando aquele apelo narcisista por alguns minutos de fama.

Enfim, também aqui Maffesoli remete à necessidade de pesquisa, reflexão, estudo para poder questionar o que aparece como valores dominantes nos meios de comunicação e informação. E insiste na atitude de astúcia, aquela forma de pensar e agir diante do que se diz, do que acontece, do que nos é imposto no dia a dia: uma divisão subjetiva implicaria uma parte em que haja concordância e comportamento correspondente, e outra em que se resiste, manipulando as duas em situações variadas. Essa atitude já é bastante reconhecida em estudos sociológicos. "Há no povo uma vitalidade que escapa às teorias elitistas e abstratas.” (MAFFESOLI, 2003, p. 20). Ou seja, a população não é passiva, sempre encontra formas de resistir no jogo da manipulação; também faz jogo duplo. 
Uma perspectiva que se ajusta a essa percepção é a manifestada por Michel Pêcheux (1982) em um de seus últimos trabalhos, relativamente a como entender, em um mundo politicamente complexo, o que se chamava ideologias dominadas, sempre sufocadas pela ideologia dominante - em uma interpretação, diz ele, populista . Ora, "as ideologias dominadas se formam sob a dominação ideológica e contra elas, e não em um 'outro mundo', anterior, exterior ou independente.” (1982, p. 63, tradução nossa). Se as práticas ideológicas são concebidas segundo rituais, como ensinava Althusser, também é necessário reconhecer que "não há ritual sem falha" (1982, p. 63). Neste ponto, Pêcheux aponta formas triviais de resistência, mais especificamente com respeito ao discurso revolucionário: não dar atenção a ordens, alterar sentidos de palavras ou enunciados, falar quando se deveria silenciar e vice-versa, jogar com as palavras - para, enfim, recusar o discurso da dominação, o discurso medido, ritualizado, legitimado (contradiscurso).

A ideologia dominante não é exercida apenas em nível nacional, e, em suma, é de seus efeitos globalizantes que se trata nas manifestações expressas acima. A cidade global, como expressão ou fórmula discursiva que circula e se quer fazer entender, é característica do século XX, prenunciando o século XXI com o recrudescimento dos processos que acompanham a expansão do capitalismo em escala mundial. Octavio Ianni (1999) mostra como essa expansão derruba todas as fronteiras entre continentes e países e como o mapa do mundo econômico se reorganizou em função dos interesses de instituições capitalistas, reconfiguradas especialmente na forma de cidades centrais, que se transformam em polos econômicos no teatro da globalização: "o mundo adquire características de uma imensa fábrica, acoplada com um vasto shopping center e colorido por uma enorme Disneylândia." (IANNI, 1999, p. 55). Visto como processo civilizatório, o capitalismo representa um processo histórico que se desenvolvia, anteriormente, como mercantilismo, colonialismo e imperialismo (1999, p. 57).

Processo civilizador ou não, que já foi conduzido pela utopia do bem-estar geral da sociedade, está implicada aí a questão social urbana, com todas as suas falhas: narcotráfico, violência, xenofobia, etnocentrismo, racismo, implicando ainda problemas de segurança, educação e saúde, áreas que não são de interesse imediato das corporações, deixadas aos cuidados do Estado (mas observadas do alto). Se a produtividade nesse mundo presumia, generalizadamente, desenvolvimento e crescimento de modo a que se vivesse no melhor dos mundos, levou, apesar disso, ao surgimento do que Ianni chama, especialmente para as grandes cidades, subclasse: "uma categoria de indivíduos, famílias, membros das mais diversas etnias e migrantes, que se encontram na condição de desempregados mais ou menos permanentes." (IANNI, 1999, p. 59), pessoas que aos poucos se desprendem das estruturas predominantes e ficam excluídas. Representam uma contradição do próprio sistema.

Há, igualmente, a exclusão na esfera da educação em geral e no campo da produção científica. As condições de produção da ciência envolvem tecnologia, inovação, impacto em tempo comprimido. Daí a controvérsia entre a política da fast science e da slow science - um efeito de resistência como aqueles tratados anteriormente, tendo parcialmente como consequência, ironicamente, uma produtividade que imita as inovações da moda em geral: sempre mudando e sempre repetindo, ou inovando na embalagem e mantendo o conteúdo. Essa realidade mostrada resiste a enunciados que, repetidos à exaustão, naturalizam-se e podem convencer: como há muita rapidez no fluxo 
de informações, tecnologias para pesquisa e necessidade de repassar conhecimento ao mundo globalizado, há pressa na disseminação, independente de outros fatores que afetam os sujeitos pesquisadores e a pesquisa em si, criando desajustes que precisam remediar de alguma forma: dividindo-se para aceitar e recusar, mas dominados ainda pelo receio de perda.

\section{A MORTE DO AUTOR, A IMPORTÂNCIA DO LEITOR, O DIREITO AUTORAL}

Barthes (2004 [1984]) tematizou, em inúmeros trabalhos, a autoria e a leitura, mostrando preocupação pela insistência em dar atenção ao autor em detrimento do leitor, em função da autoridade daquele e de seu projeto de criação, enquanto as manifestações de leitura representavam uma abertura para o insólito dos múltiplos sentidos. Reconhecia, contudo, o movimento heterogêneo de produção de leitura, dando espaço para uma reflexão sobre "a morte do autor", quando já reconhecíamos a também instigante noção de função-autor tal como Foucault a desenhava e explicava - também ele deixando entender, aparentemente, que se tratava do acompanhamento a outro desígnio: a morte do homem. Não era precisamente disso que ele tratava, como é possível seguir, em detalhe, o caso na obra $O$ que é um autor?, que não vamos tematizar aqui ${ }^{1}$.

Ao dizer que a escritura faz desaparecer a origem, a voz que enuncia, Barthes (2004 [1984]) vê a escrita como uma zona cinzenta que não guarda uma identidade, quer dizer, faz desaparecer quem escreve (daí a ideia de função subjetiva em Foucault), e anuncia uma construção subjetiva em porvir, tramando-se. O autor é uma exterioridade que silencia. Por outro lado, aquele que recebe esse tecido, uma vez liberado, é o leitor, que surge como uma potência recriadora. Por isso Barthes considera que é no destino do texto que se encontra sua unidade, seu reconhecimento.

Embora o reconhecimento da potência do leitor não possa ser descartado, especialmente por quem vive na prática da escrita - é um aspecto fundamental do tema aqui em desenvolvimento, a comunicação (partilha sensitiva) como vimos em Maffesoli, bem como o trabalho do imaginário a cimentar as interações -, sabemos que em nossa formação social o prestígio do indivíduo garante, para o bem ou para o mal (um escritor pode ser acusado), que há direitos específicos sobre escritos e obras a proteger, o que nos leva a cuidados tão excessivos que algo começa a romper o delicado tecido que une tribos, grupos específicos, sociedades em sua sensibilidade e harmonia.

Maffesoli (2008, p. 8), na linha de sua sociologia compreensiva, destaca: "Simbólico é nascer reconhecendo o outro. A comunicação pós-moderna é o retorno do simbólico pré-moderno. Eu só existo através e sob o olhar do outro.” É uma posição de contrariedade ao suposto potencial de poder e valor do individualismo, que conduz a confrontos de obtenção de superioridade à custa de outrem - competição em toda parte e para qualquer coisa: esporte, ciência, riqueza, posição política, beleza, moda... Não apenas ser melhor em sua vida, mas ser superior a outrem. Esse jogo é satisfeito com estímulos, desde a simples torcida até a estipulação de prêmios em concursos de todo tipo.

\footnotetext{
${ }^{1}$ O tema foi discutido na apresentação da edição 2017-3 da Linguagem em (Dis)curso.
} 
Ao tematizar o plágio em geral como mecanismo de apagamento da autoria, e ao mesmo tempo lembrando os processos da heterogeneidade discursiva, cujo efeito é o inevitável atravessamento de textos (intertextualidade) na produção discursiva, Orlandi (1992) fez ressurgir um slogan que enuncia: "os sentidos não têm dono", que claramente não floresce em nosso mundo. Contudo, ao distinguir um movimento que ela chamou meio-plágio, ocorrendo em materiais acadêmicos e provavelmente sem efeito de mera cópia nem necessariamente má intenção, observou que havia apagamento de algumas filiações, deixando esquecidos os trajetos autorais - como se o produtor estivesse assumindo que não há, de fato, proprietários para os sentidos (ou palavras, expressões, teorias, perspectivas, experiências, enfim), tomando-os para si naquele momento, como empréstimo de um tesouro disponível.

Orlandi sugere, então, a possibilidade de essa espécie de esquecimento estar manifestando "um sintoma de uma mudança na função da autoria." (ORLANDI, 1992, p. 147). Isso estaria significando algum deslocamento efetivo da noção de autoria? Ainda que esse movimento se repita muitas vezes (o controle não é tão fácil), certamente, como a autora nota, nossa formação social não se transformou o suficiente para incorporar tal fenômeno. Na verdade, recrudesce o esforço para a detecção de toda a variedade de plágio e, mais recentemente, de autoplágio ${ }^{2}$ (cópia de si, repetição produtiva), que está vinculado, como vemos aqui, ao processo de astúcia de que fala Maffesoli, como forma de resistência à pressão constante sofrida especialmente no meio acadêmico - mas, que se diga também, que acomete os iniciantes em pesquisa quando não têm, ainda, suficiente autonomia autoral e a necessária orientação quanto à normatização para a produção autoral (tema que merece atenção contínua desde o início do aprendizado de escrita da língua).

\section{PRODUTIVIDADE, MERCANTILIZAÇÃO DA CIÊNCIA E DIVULGAÇÃO}

Sabemos que a textualização de ideias, de conhecimentos, de literatura, em qualquer área, com resultados mais ou menos satisfatórios, depende de busca, de leitura, de um conjunto enciclopédico exterior e de experiências de grupo, além de experimentos, trabalho de campo, laboratórios, que necessariamente mostram um jogo em duas direções: para o passado, de onde se aproveita o que já foi produzido em todas as áreas, e que se resume em repetição do conhecimento (retomada, paráfrase, citação); e para o porvir, para movimento novo, que apresenta miríades de facetas: o deslocamento, a inovação, a mudança - o que pode produzir a função autoral e, mais propriamente, o efeito-autor. São dois movimentos básicos da própria dinâmica geral da linguagem, que Orlandi, em perspectiva discursiva, propõe com as noções genéricas de paráfrase e polissemia (cf. ORLANDI, 1987, p. 137). Daqui deriva a correlação que ela faz, respectivamente, com produtividade e criatividade. A produtividade se engendra a partir de uma matriz, de um tesouro de conhecimento - a memória (em suas variantes). A criatividade representa o que emerge como novidade, algo da ordem do que não foi dito ou não foi feito, ou alguma mudança, deslizamento, ruptura, crítica, proposta de novo trajeto, enfim. Presentifica-se o efeito de posicionamento, avaliação, reapreciação.

\footnotetext{
${ }^{2}$ V. apresentação da edição 2018-1 da Linguagem em (Dis)curso.
} 
O problema que nos toca, aqui, é produzir trabalho científico - produzir remete de imediato a produtividade, embora a perspectiva e a exigência sejam de criatividade. Primeira contradição: deseja-se originalidade, não repetição, e ineditismo, não divulgação de cópias ou semicópias, mesmo porque há também regras para a reprodução de trabalhos. No entanto, não há ineditismo sem repetição (paráfrase), assim como não há, rigorosamente, repetição sem algum tipo de deslizamento, porque espaço-tempo e subjetividade não se repetem; o que pode haver é erro, falsificação, dissimulação. Um continuum de possibilidades se apresenta no que pode ser enunciado, e é isso que ocorre e que abre caminho para a dificuldade de julgamento quanto ao que se denomina plágio ou autoplágio, paralelamente à dificuldade de determinação do que seja original. Assim é que cada produto científico que se ofereça ao olhar ou leitura alheia é, em última análise, uma caixa de surpresas que se abre com suspeição, em nosso modo de avaliação (ou mesmo tratando-se de leitor sem prevenção), suspeição que dirigimos convenientemente ao sujeito-autor, seja ele membro de grupo de que fazemos parte ou de outro grupo qualquer, e relativamente à posição que ocupamos como leitor. Da mesma forma, cada um de nós é pessoalmente suspeito aos olhos de outrem. Basta que leiamos a política de publicação dos periódicos em geral para nos certificarmos disso.

As possibilidades de plágio atingiram número tão elevado que, periodicamente, vemos listas que nos alertam sobre formas de falseamento de produção alheia - a ponto de também acreditarmos que autores plagiados poderiam, por sua vez, ter plagiado outrem. Isso se concretiza como uma caça às bruxas. $\mathrm{O}$ que se forja nesse círculo de desconfiança mútua não é, certamente, vantajoso para ninguém, sobretudo para quem, ao lado da função de pesquisar, deve ensinar, orientar pesquisas de iniciação científica, mestrado e doutorado, além de, comumente, ser consultor de periódicos, e por vezes também editor. $\mathrm{O}$ jogo em processo leva àquilo de que nos previne Maffesoli: o jogo duplo e as astúcias que buscam equilibrar a subjetividade naquilo que nos prende aos outros, pelo imaginário.

A luta pela produtividade, estimulada por nossas agências estatais e, mais distante e acima, por setores que só estão interessados em educação e ciência pelos frutos que podem colher para proveito específico, especialmente da ciência dura, não é necessariamente refletida na alta qualidade de uma produção, mas deve ser conveniente estimular a competitividade e premiá-la esporadicamente. Se o financiamento para a pesquisa é um aspecto positivo (embora também se reduza periodicamente e, sobretudo, para certas áreas), universidades e institutos de pesquisa precisariam ser livres para planejar as próprias metas e meios em conformidade com objetivos amplos e não atrelados a mecanismos de controle mercadológicos.

Isto considerado, sem que se pretenda meramente escusar ou aceitar o movimento astucioso de abrir fissuras ou aproveitar-se delas na luta pela produtividade, entendemos que, pelos frutos que temos colhido com tais atitudes, é hora de compreender e negociar, lembrando que a proliferação de meios de inibição nos diz claramente que há um problema: algo falta e algo excede, e não apenas de um lado. O velho ditado A pressa é inimiga da perfeição é um bom mote nesta situação. Festejemos a slow science, ou seja, a ciência lúcida. 
BARTHES, R. O rumor da língua. São Paulo: Martins Fontes, 2004 [1984].

IANNI, O. A era do globalismo. 4. ed. Rio de Janeiro: Civilização Brasileira, 1999.

MAFFESOLI, M. Liberdades intersticiais. In: MORIN, E.; BAUDRILLARD, J.: MAFFESOLI, M. A decadência do futuro e a construção do presente. Florianópolis: Editora da UFSC, 1993.

Mediações simbólicas: a imagem como vínculo social. Revista FAMECOS, Porto Alegre, n. 8, p. 7-14, jul. 1998

O imaginário é uma realidade. Revista FAMECOS, Porto Alegre, n. 15, p. 74-82, ago. 2001.

A comunicação sem fim (teoria pós-moderna da comunicação). Revista FAMECOS, Porto

Alegre, n. 20, p. 13-20, abr. 2003.

A terra fértil do cotidiano. Revista FAMECOS, Porto Alegre, n. 36, p. 5-9, ago. 2008.

ORLANDI, E. P. A linguagem e seu funcionamento: as formas do discurso. 2. ed. rev. e aum. Campinas: Editora Pontes, 1987.

. As formas do silêncio: no movimento dos sentidos. Campinas: Ed. Unicamp, 1992.

PÊCHEUX, M. Délimitations, retournements et déplacements. L'Homme et la Société, n. 63-64, p. 53-69, 1982.

WACHOWICZ, M.; COSTA, J. A. F. Plágio acadêmico. Curitiba: Gedai Publicações, 2016.

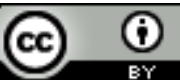

Este texto está licenciado com uma Licença Creative Commons Atribuição 4.0 Internacional. 